\title{
Association between the elderly frequent attender to the emergency department and 30-day mortality: A retrospective study over 10 years
}

\author{
Yuzeng Shen ${ }^{1}$, Yee Chien Tay ${ }^{2}$, Edward Wee Kwan Teo ${ }^{3}$, Nan Liu ${ }^{4}$, Shao Wei Lam ${ }^{4}$, Marcus Eng Hock Ong ${ }^{1}$ \\ ${ }^{1}$ Department of Emergency Medicine, Singapore General Hospital, Singapore \\ ${ }^{2}$ Department of Emergency Medicine, Sengkang Health, Singapore \\ ${ }^{3}$ Business Analytics Program, National University of Singapore, Singapore \\ ${ }^{4}$ Singhealth Health Services Research Centre, Singapore
}

Corresponding Author: Yuzeng Shen, Email: shen.yuzeng@singhealth.com.sg

BACKGROUND: To determine if elderly frequent attenders are associated with increased 30day mortality, assess resource utilization by the elderly frequent attenders and identify associated characteristics that contribute to mortality.

METHODS: Retrospective observational study of electronic clinical records of all emergency department (ED) visits over a 10-year period to an urban tertiary general hospital in Singapore. Patients aged 65 years and older, with 3 or more visits within a calendar year were identified. Outcomes measured include 30-day mortality, admission rate, admission diagnosis and duration spent at ED. Chi-square-tests were used to assess categorical factors and Student $t$-test was used to assess continuous variables on their association with being a frequent attender. Univariate and multivariate logistic regressions were conducted on all significant independent factors on to the outcome variable (30-day mortality), to determine factor independent odds ratios of being a frequent attender.

RESULTS: 1.381 million attendance records were analyzed. Elderly patients accounted for $25.5 \%$ of all attendances, of which $31.3 \%$ are frequent attenders. Their 30 -day mortality rate increased from $4.0 \%$ in the first visit, to $8.8 \%$ in the third visit, peaking at $10.2 \%$ in the sixth visit. Factors associated with mortality include patients with neoplasms, ambulance utilization, male gender and having attended the ED the previous year.

CONCLUSION: Elderly attenders have a higher 30-day mortality risk compared to the overall ED population, with mortality risk more marked for frequent attenders. This study illustrates the importance and need for interventions to address frequent ED visits by the elderly, especially in an aging society.

KEY WORDS: Frequent attenders; Elderly; Emergency department; Mortality

World J Emerg Med 2018;9(1):20-25

DOI: 10.5847/wjem.j.1920-8642.2018.01.003

\section{INTRODUCTION}

An aging society in Singapore has led to a growing proportion of elderly patients with more complex comorbidities visiting the emergency department (ED) ${ }^{[1]}$ The numbers of ED visits by elderly patients are increasing, ${ }^{[2]}$ with a study demonstrating a $34 \%$ increase in elderly attenders over 10 years. ${ }^{[3]}$ From the resource utilization perspective, the ED frequent attender (FA) has been found to contribute disproportionately to crowding, ${ }^{[4,5]}$ a phenomenon associated with increased mortality and other poor outcomes. ${ }^{[6-7]}$

Elderly ED attenders are associated with increased ambulance use, higher acuity conditions, longer length of stay at the ED and higher admission rates. ${ }^{[8-10]}$ Although the elderly and poor outcomes are both associated with ED FAs, no study has specifically assessed the elderly FA, 
with regards to their outcomes, especially mortality. Studies demonstrating increased mortality for elderly ED attenders are relatively small in sample size and the relationship with respect to visit frequency is unknown. ${ }^{[11,12]}$

We aim to determine if elderly FAs are associated with increased 30-day mortality. The study would also assess resource utilization by the elderly FA, and identify associated clinically relevant patient and visit characteristics, with regards to mortality. We postulate that the elderly FA is associated with increased 30-day mortality rate, whether compared against the elderly nonFA or the non-elderly FA.

\section{METHODS}

\section{Study design}

A retrospective observational study of electronic medical records of all visits to the ED over a 10-year period from January 2005 to December 2014 was performed. We obtained institutional review board approval for the study.

\section{Study settings and population}

Singapore is an urban city state with a population of 5.6 million. ${ }^{[1]}$ The study institution is the largest hospital in Singapore with 1,600 inpatient beds, and provides tertiary care to a significant section of the population. It is part of the Singhealth Regional Health System (RHS) which covers a population of more than 1.1 million and receives more than 4 million patient visits yearly. The Department of Emergency Medicine receives more than 140,000 patient visits annually.

\section{Study protocol}

The data was generated from the Electronic Health Intelligence System (eHINTS), a data warehouse which compiles data from several hospital databases patient health records, ED registration, admissions and death registry. We masked specific details pertaining to patients, their attendances and subsequent admissions, to ensure that data was adequately anonymized, while remaining able to identify the same patient regardless of the number of repeated visits within the study dataset.

Other variables include the date and time-stamps upon the ED registration, consultation, disposition; the mode of arrival, triage class, vital signs readings, diagnosis given at the ED, admissions and discharge data. Death records were drawn from the Singhealth death registry, and matched to the visit entries of the specific patient.

\section{Definitions and outcomes}

We define the ED frequent attender within our population as having three or more visits to ED over a calendar year, based on a resource utilization and outcomes model. ${ }^{[13]}$ The 30 -day mortality rate was defined as the death of the patient from all causes, within 30 days of registration of an ED attendance.

Time to consultation was defined as the duration between patient registration upon arrival at ED, to the time of initiation of physician consult. Time to disposition was defined as the duration between when consultation was initiated, to the time patient disposition was made. Further outcomes assessed include the patient's diagnosis on admission, rate of admissions to the emergency observation ward and inpatient wards, and the inpatient length of stay. We sorted admission diagnosis based on the International Classification of Diseases, Ninth Revision.

\section{Data analysis}

The SAP (SAP SE, Walldorf, Germany) relational database management system was used to calculate variables in the study data set, such as "time to consultation", "length of stay" and "attendance this year". Further data preparation and analysis was performed using R v3.2.3 (R Foundation, Vienna, Austria).

Among the attendances within the " 65 \& above" age group, the Chi-square-tests was used to assess categorical factors and the Student $t$-test was used to assess continuous variables on their association with being a FA. All demographic profile and attendance characteristic factors available were found to reject the null hypothesis that they were independent to the target variable of being a frequent attender at the $95 \%$ significance level $(P$-value of 0.05 ).

Univariate logistic regression was conducted on all significant independent factors to the outcome variable (30-day mortality), to determine factor independent odds ratios of being an FA. Multivariate logistic regression was also conducted to determine the adjusted odds ratios.

\section{RESULTS}

There were 1.383 million unique patient visits over the period of 1 January 2005 to 31 December 2014. 1,715 records (or $0.001 \%$ ) were removed from the dataset as they were either dead on arrival (1,681 records) or lacked basic demographic data (34 records). There were no other exclusion criteria. 
The remaining 1.381 million patient visits were analyzed. The attendances by $65 \&$ above year olds (at time of attendance) accounted for $25.5 \%(353,042)$ of all attendances to SGH ED over 2005 to 2014. Among the $65 \&$ above year olds, $31.3 \%$ (or 110,671) of the attendances were by FAs, and the remaining $68.7 \%$ (or 242,371 ) by non-FAs (Figure 1).

\section{General attendances of elderly ED attenders}

The total number of patients aged 65 years and above has been increasing over the 10 -year period of analysis. The proportion of FAs among the " 65 \& above" attendances remained relatively constant at around $31.3 \%$ (Table 1), higher than the $22.1 \%$ at the overall level. In terms of unique attenders (within each calendar year), FAs accounted for $11.7 \%$ of attendances of 65 and above years of age. This was also higher than the 7.0\% level among all attendances.

\section{Patient and visit characteristics of elderly ED attenders}

All demographic and attendance factors available were found to be significantly dependent to the target variable (being a frequent attender) at the $95 \%$ significance level, except "admission length of stay" and the 30-day mortality rate.

"65 \& above" attendances had a disproportional share of "Chinese" ethnicity, regardless if they are FA or non-FA. The proportion of "Chinese" ethnicity among "65 \& above" was more than $80 \%$, compared to about $65 \%$ among all attendances (Table 2).

FAs had a higher proportion of those " $85 \&$ above"

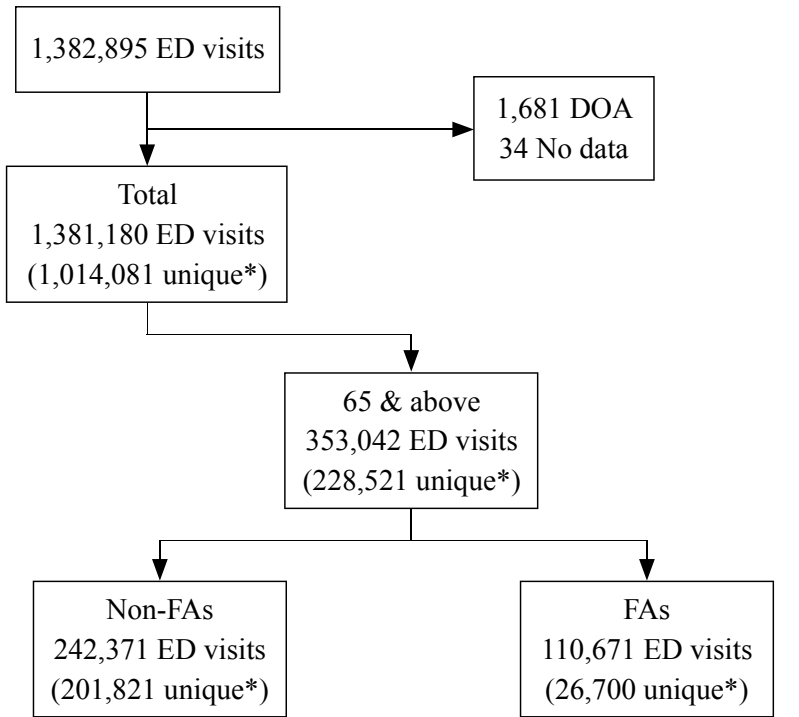

Figure 1. 65 \& above, data selection of non-frequent attenders (FAs) and FAs.
(15.4\%), compared to non-FAs (11.8\%). Their share of P1 or $\mathrm{P} 2$ triage class was $76.9 \%$, higher than that of the nonFAs at $67.2 \% .60 .7 \%$ of FAs had attended at least once in the previous year, more than double the $27.9 \%$ of non-FAs.

\section{Outcome characteristics}

Admission rates for FAs were higher than nonFAs, at $70.8 \%$ and $57.4 \%$ (Table 3), respectively. In terms of diagnosis, there were also higher proportion of FA patients with "respiratory diseases", "immunity

Table 1. Average per year FA3 attendance by period, 2005-2014

\begin{tabular}{lcc}
\hline Parameters & $\begin{array}{c}\text { All attendance } \\
(n=1,381,180)\end{array}$ & $\begin{array}{c}65 \& \text { above attendance } \\
(n=353,042)\end{array}$ \\
\hline Average per year & & \\
$\quad$ Total attendance & 138,118 & 35,304 \\
$\quad$ FA attendance & 30,523 & 11,067 \\
FA share of attendance & 22.1 & 31.3 \\
Average per year & & \\
$\quad$ Unique attendance & 101,408 & 6,982 \\
$\quad$ Unique FA attendance & 7,121 & 816 \\
FA share of unique attendance & 7.0 & 11.7 \\
\hline
\end{tabular}

Table 2. Patient and visit characteristics of $65 \&$ above non-frequent attenders (FAs) vs. FAs, 2005-2014

\begin{tabular}{|c|c|c|c|}
\hline Parameters & $\begin{array}{l}65 \& \text { above non-FA } \\
(n=242,371)\end{array}$ & $\begin{array}{l}65 \& \text { above FA } \\
(n=110,671)\end{array}$ & $P$ values \\
\hline Gender & & & $<0.001$ \\
\hline Female & 54.0 & 51.5 & \\
\hline Male & 46.0 & 48.5 & \\
\hline Age & & & - \\
\hline $65 \&$ above & 100.0 & 100.0 & \\
\hline $85 \&$ above & 11.8 & 15.4 & \\
\hline Ethnicity & & & $<0.001$ \\
\hline Chinese & 81.8 & 80.2 & \\
\hline Malay & 7.3 & 8.6 & \\
\hline Indian & 7.1 & 8.7 & \\
\hline Others & 3.7 & 2.5 & \\
\hline \multicolumn{4}{|l|}{ Distance to SGH-ED } \\
\hline 0 to $<5 \mathrm{~km}$ & 29.0 & 32.8 & \\
\hline 5 to $<10 \mathrm{~km}$ & 29.1 & 26.1 & \\
\hline 10 to $<15 \mathrm{~km}$ & 27.2 & 26.8 & \\
\hline $15 \mathrm{~km}$ or more & 14.7 & 14.4 & \\
\hline Transport & & & $<0.001$ \\
\hline Ambulance & 19.6 & 23.9 & \\
\hline Day of attendance & & & $<0.001$ \\
\hline Monday & 16.6 & 15.8 & \\
\hline Tuesday & 14.7 & 14.6 & \\
\hline Wednesday & 14.1 & 14.1 & \\
\hline Thursday & 14.1 & 14.1 & \\
\hline Friday & 14.3 & 14.2 & \\
\hline Saturday & 14.0 & 14.1 & \\
\hline Sunday & 12.3 & 13.2 & \\
\hline Time of attendance & & & $<0.001$ \\
\hline 00:00-05:59 hours & 6.5 & 8.8 & \\
\hline 06:00-11:59 hours & 29.9 & 29.0 & \\
\hline $12: 00-17: 59$ hours & 39.5 & 36.0 & \\
\hline 18:00-23:59 hours & 24.1 & 26.2 & \\
\hline Triage priority & & & $<0.001$ \\
\hline P1 & 13.9 & 17.3 & \\
\hline $\mathrm{P} 2$ & 53.3 & 59.6 & \\
\hline $\mathrm{P} 3 / \mathrm{P} 4$ & 32.8 & 23.1 & \\
\hline Attended previous year & 27.9 & 60.7 & $<0.001$ \\
\hline FA with 3-6 visits & - & 81.2 & - \\
\hline FA with 7 or more visits & - & 18.8 & - \\
\hline
\end{tabular}


disorders", and "genitourinary diseases", compared to non-FAs. Conversely, there were lower proportions of "injury and poisoning" and "nervous diseases" among FAs, compared to non-FAs.

\section{0-day mortality rates between age groups}

The 30-day mortality rate, defined as the death of the patient from all causes within 30 days of registration of an ED attendance, was the $5.4 \%$ among patients aged 65 years \& above, whether they were FAs or non-FAs. Examination of the 30-day mortality rate by the numbered visits (within a calendar year), differentiated by age group among all attendances (Figure 2) reveals the 30-day mortality rate for attenders aged $65 \&$ above years old to be higher than that of younger patients. This implies that patients 65 years old $\&$ above had a higher mortality risk compared to those who are less than 65 years of age.

Among the older $65 \&$ above, their 30-day mortality rate increased from $4.0 \%$ in the first visit, to $8.8 \%$ in the third visit. It continued to increase, peaking at $10.2 \%$ at the sixth visit, before trending downwards on subsequent additional visits, suggesting that re-attenders have a higher 30-day mortality risk over the 3 rd to 6 th visit within a calendar year.

\section{Factors associated with 30-day mortality for elderly frequent attenders}

In terms of diagnosis-related factors (Table 4),

Table 3. Outcome characteristics of $65 \&$ above non-frequent attenders (FAs) vs. FAs, 2005-2014

\begin{tabular}{|c|c|c|c|}
\hline Parameters & $\begin{array}{l}65 \& \text { above non-FA } \\
(n=242,371)\end{array}$ & $\begin{array}{l}65 \& \text { above FA } \\
(n=110,671)\end{array}$ & $P$-values \\
\hline $\begin{array}{l}\text { Median time to } \\
\text { consultation }\end{array}$ & 36 & 32 & $<0.001$ \\
\hline $\begin{array}{l}\text { Median time to } \\
\text { disposition }\end{array}$ & 189 & 198 & $<0.001$ \\
\hline \multicolumn{4}{|l|}{ Admission } \\
\hline Admitted & 57.4 & 70.8 & $<0.001$ \\
\hline $\begin{array}{l}\text { Length of stay } \\
\text { (median) }\end{array}$ & 6 & 6 & 0.803 \\
\hline Admission diagnosis & & & $<0.001$ \\
\hline Infectious diseases & 6.7 & 7.5 & \\
\hline Neoplasms & 2.5 & 3.3 & \\
\hline Immunity disorders & 5.3 & 7.9 & \\
\hline Blood diseases & 1.3 & 1.5 & \\
\hline Mental disorders & 0.3 & 0.4 & \\
\hline Nervous diseases & 4.3 & 1.9 & \\
\hline Circulatory diseases & 13.2 & 13.4 & \\
\hline Respiratory diseases & 8.6 & 12.0 & \\
\hline Digestive diseases & 8.3 & 9.0 & \\
\hline $\begin{array}{l}\text { Genitourinary } \\
\text { diseases }\end{array}$ & 3.7 & 5.6 & \\
\hline Skin diseases & 3.9 & 3.6 & \\
\hline Musculoskeletal & 4.9 & 3.7 & \\
\hline General symptoms & 23.5 & 24.5 & \\
\hline Injury and poisoning & 13.2 & 5.7 & \\
\hline ED observation ward & 4.0 & 2.5 & $<0.001$ \\
\hline 30 -day mortality rate & 5.4 & 5.4 & 0.764 \\
\hline
\end{tabular}

"neoplasms disorders" $5.32(4.97,5.69)$ exhibited the highest adjusted odds ratios (AdjOR) of mortality among the diagnoses. Conversely, "nervous diseases" $0.25(0.21$, $0.29)$, "musculoskeletal diseases" $0.31(0.27,0.36)$, "injury and poisoning" $0.32(0.29,0.35)$, and "mental disorders" $0.33(0.22,0.48)$ had the lowest AdjOR (Table 4).

Non-diagnosis factors with the highest AdjOR were transport "ambulance" $2.72(2.63,2.81)$, "attend previous year" $1.26(1.22,1.31)$, and gender "male" 1.21 (1.17, $1.25)$. Factors associated with lower odds of 30-day mortality included: triage $\mathrm{P} 3 / \mathrm{P} 40.14(0.13,0.15)$, triage "P2" $0.45(0.43,0.46)$, and FA "7 or more visits" 0.36 $(0.33,0.40)$. FAs who were admitted to the ED observation ward also reflected low odds of mortality $0.14(0.11,0.17)$.

\section{DISCUSSION}

Our results show that elderly ED attenders aged 65 years and above, are associated with increased 30-day mortality risk, compared to ED attenders in general. Compared to patients aged less than 65 years old, elderly patients demonstrate up to 5 times the latter's 30-day mortality risk, with maximal divergence during the 3rd to 6th ED visit over a calendar year. Previous studies reflect a mortality rate from $9 \%$ to $12 \%$, but involved smaller cohorts of patients and did not segregate patients by frequency of visit..$^{[1,12]}$

Elderly FAs contribute disproportionately, to both the total number of elderly patient visits to the ED and the ED resources utilized ${ }^{[13,14]}$ Compared to the elderly non-FAs, they are associated with increased utilization of ambulances and have higher rates of admission rates from the ED. However, in our study population, despite having a higher triage acuity and proportion of patients aged 85 years and older, elderly FAs do not have increased time to disposition at ED or increased inpatient length of stay. There is no significant difference in 0 -day mortality rates between the FAs and non-FAs for patients aged 65 years and older.

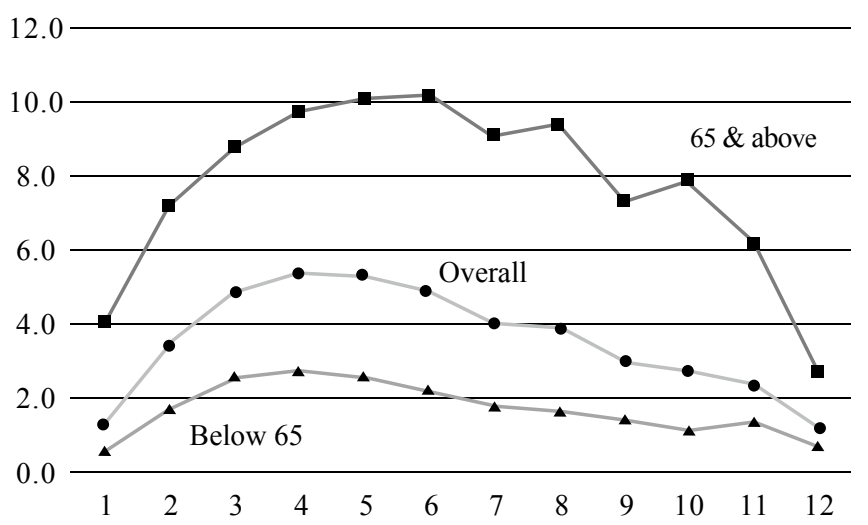

Figure 2. 30-day mortality rates by the numbered visit. 
Table 4. Univariate and multivariate analysis of factors associated with 30-day mortality

\begin{tabular}{|c|c|c|c|c|}
\hline \multirow{2}{*}{$\begin{array}{l}\text { Parameters } \\
\text { Gender }\end{array}$} & \multicolumn{2}{|c|}{$\begin{array}{l}\text { Univariate } \\
\text { odds ratio }\end{array}$} & \multicolumn{2}{|c|}{$\begin{array}{l}\text { Multivariate } \\
\text { adjusted odds ratio }\end{array}$} \\
\hline & & & & \\
\hline Female & 1 & & & \\
\hline Male & 1.36 & $(1.33,1.4)$ & 1.21 & $(1.17,1.25)$ \\
\hline \multicolumn{5}{|l|}{ Age } \\
\hline $65 \&$ above & - & & - & \\
\hline \multicolumn{5}{|l|}{ Ethnicity } \\
\hline Chinese & 1 & & & \\
\hline Malay & 0.98 & $(0.93,1.04)$ & 0.93 & $(0.88,0.99)$ \\
\hline Indian & 0.65 & $(0.61,0.70)$ & 0.69 & $(0.64,0.74)$ \\
\hline Others & 0.67 & $(0.61,0.73)$ & 0.64 & $(0.58,0.71)$ \\
\hline \multicolumn{5}{|l|}{ Distance to SGH-ED } \\
\hline 0 to $<5 \mathrm{~km}$ & 1 & & & \\
\hline 5 to $<10 \mathrm{~km}$ & 0.91 & $(0.88,0.95)$ & 1.16 & $(1.12,1.21)$ \\
\hline 10 to $<15 \mathrm{~km}$ & 0.91 & $(0.87,0.94)$ & 1.15 & $(1.11,1.20)$ \\
\hline $15 \mathrm{~km}$ or more & 0.96 & $(0.92,1.01)$ & 1.19 & $(1.13,1.25)$ \\
\hline \multicolumn{5}{|l|}{ Transport } \\
\hline Ambulance & 4.27 & $(4.15,4.4)$ & 2.72 & $(2.63,2.81)$ \\
\hline \multicolumn{5}{|l|}{ Day of attendance } \\
\hline Monday & 1.01 & $(0.96,1.06)$ & 1.03 & $(0.97,1.09)$ \\
\hline Tuesday & 0.99 & $(0.94,1.04)$ & 1.00 & $(0.94,1.06)$ \\
\hline Wednesday & 1.01 & $(0.96,1.07)$ & 1.01 & $(0.95,1.07)$ \\
\hline Thursday & 0.99 & $(0.93,1.04)$ & 0.98 & $(0.92,1.04)$ \\
\hline Friday & 1 & & & \\
\hline Saturday & 0.98 & $(0.92,1.03)$ & 0.97 & $(0.91,1.03)$ \\
\hline Sunday & 1.14 & $(1.08,1.20)$ & 1.04 & $(0.98,1.11)$ \\
\hline \multicolumn{5}{|l|}{ Time of attendance } \\
\hline 00:00-05:59 hours & 1 & & & \\
\hline 06:00-11:59 hours & 0.76 & $(0.72,0.80)$ & 1.10 & $(1.04,1.18)$ \\
\hline 12:00-17:59 hours & 0.81 & $(0.77,0.86)$ & 1.19 & $(1.12,1.27)$ \\
\hline 18:00-23:59 hours & 0.94 & $(0.89,0.99)$ & 1.17 & $(1.10,1.24)$ \\
\hline \multicolumn{5}{|l|}{ Triage priority } \\
\hline P1 & 1 & & & \\
\hline $\mathrm{P} 2$ & 0.34 & $(0.33,0.35)$ & 0.45 & $(0.43,0.46)$ \\
\hline $\mathrm{P} 3 / \mathrm{P} 4$ & 0.06 & $(0.06,0.07)$ & 0.14 & $(0.13,0.15)$ \\
\hline Attend previous year & 1.34 & $(1.30,1.38)$ & 1.31 & $(1.26,1.35)$ \\
\hline FA & 1.00 & $(0.97,1.04)$ & - & \\
\hline 3-6 visits & 1.15 & $(1.12,1.19)$ & 0.77 & $(0.75,0.80)$ \\
\hline 7 or more visits & 0.54 & $(0.50,0.59)$ & 0.36 & $(0.33,0.40)$ \\
\hline Time to consultation & 0.99 & $(0.98,0.99)$ & 1.00 & $(1.00,1.00)$ \\
\hline Time to disposition & 1.00 & $(1.00,1.00)$ & 1.00 & $(1.00,1.00)$ \\
\hline \multicolumn{5}{|l|}{ ED diagnosis } \\
\hline Infectious diseases & 1 & & & \\
\hline Neoplasms & 4.32 & $(4.06,4.59)$ & 5.32 & $(4.97,5.69)$ \\
\hline Immunity disorders & 0.68 & $(0.64,0.73)$ & 0.75 & $(0.69,0.80)$ \\
\hline Blood diseases & 0.74 & $(0.66,0.83)$ & 1.03 & $(0.91,1.16)$ \\
\hline Mental disorders & 0.23 & $(0.16,0.34)$ & 0.33 & $(0.22,0.48)$ \\
\hline Nervous diseases & 0.12 & $(0.10,0.14)$ & 0.25 & $(0.21,0.29)$ \\
\hline Circulatory diseases & 0.55 & $(0.52,0.59)$ & 0.53 & $(0.49,0.56)$ \\
\hline Respiratory diseases & 1.06 & $(1.00,1.12)$ & 0.96 & $(0.90,1.02)$ \\
\hline Digestive diseases & 0.47 & $(0.44,0.50)$ & 0.73 & $(0.68,0.79)$ \\
\hline Genitourinary diseases & 0.56 & $(0.51,0.61)$ & 0.90 & $(0.83,0.98)$ \\
\hline Skin diseases & 0.25 & $(0.23,0.28)$ & 0.70 & $(0.62,0.79)$ \\
\hline Musculoskeletal diseases & 0.12 & $(0.10,0.13)$ & 0.31 & $(0.27,0.36)$ \\
\hline Symptoms & 0.36 & $(0.34,0.39)$ & 0.60 & $(0.56,0.64)$ \\
\hline Injury and poisoning & 0.17 & $(0.16,0.19)$ & 0.32 & $(0.29,0.35)$ \\
\hline ED observation ward & 0.09 & $(0.07,0.12)$ & 0.14 & $(0.11,0.17)$ \\
\hline
\end{tabular}

There have been studies done with regards to predicting repeat attendances to the ED for the elderly. ${ }^{[15-17]}$ Interventions such as multi-disciplinary case management, with social workers, community and primary health care partners have been shown to reduce the frequency of visits to the ED. ${ }^{[18]}$ We have identified various factors associated with 30-day mortality, which can help towards the development of a clinically relevant algorithm to identify elderly FAs at the extremes of risk for adverse outcomes. Identifying these at risk patients in a data-driven manner would maximize the utility of resource intensive multidisciplinary case management efforts, by targeting high yield patients in an efficient manner.

\section{Limitations}

The retrospective study design meant that we were unable to collect data not included within the primary study data set. We were unable to determine the appropriateness or necessity of each ED visit, which would have provided a more granular perspective of study findings. There is also a lack of data regarding other important aspects of care for the elderly at the ED, such as assessing physical and cognitive states and for functional problems.

As the study was limited to a single study site, we were unable to reference visits that each unique patient may have made to other EDs within the country, or reference mortality events with the national death registry. It is possible that we may have underestimated the total number of ED visits per patient, when visits to other EDs are included. This is mitigated by the large study sample size and significant regional coverage by the Singhealth RHS. Variables and outcomes analyzed were also broad and clinically relevant.

\section{CONCLUSION}

Elderly attenders to the ED have a higher 30-day mortality risk compared to the overall ED population, with mortality risk being more marked for frequent attenders. Elderly frequent attenders also demonstrate different resource utilization patterns compared to the overall ED population. This study illustrates the need for interventions to reduce the elderly patient's frequency of visits to the ED, especially in the context of an aging society.

\section{ACKNOWLEDGMENTS}

The authors thank Mr Sherman Lian from the Department of Emergency Medicine, Singapore General Hospital, for his assistance in data collation. 
Funding: None.

Ethics approval:We obtained institutional review board approval for the study.

Competing interests: The authors declare that there are no conflicts of interest related to the publication of this paper.

Contributions: Conception and design of study: YS, EWKT, NL, MEHO. Analysis and interpretation of data: YS, YCT, EWKT, NL, SWL, MEHO. Revising the manuscript critically for important intellectual content: YS, YCT, NL, SWL, MEHO. Approval of the version of the manuscript to be published: YS, YCT, EWKT, NL, SWL, MEHO.

\section{REFERENCES}

1 Department of Statistics, Ministry of Trade \& Industry R of S. Population Trends, 2016; 2016.

2 Aminzadeh F, Dalziel WB. Older adults in the emergency department: a systematic review of patterns of use, adverse outcomes, and effectiveness of interventions. Ann Emerg Med. 2002;39(3):238-47.

3 Roberts DC, Mckay MP, Shaffer A. Increasing rates of emergency department visits for elderly patients in the United States, 1993 to 2003. Ann Emerg Med. 2008;51(6):769-74.

4 Hunt KA, Weber EJ, Showstack JA, Colby DC, Callaham ML. Characteristics of frequent users of emergency departments. Ann Emerg Med. 2006;48(1):1-8.

5 LaCalle E, Rabin E. Frequent users of emergency departments: the myths, the data, and the policy implications. Ann Emerg Med. 2010;56(1):42-8.

6 Derlet RW. Overcrowding in emergency departments: increased demand and decreased capacity. Ann Emerg Med. 2002;39(4):430-2.

7 Hoot NR, Aronsky D. Systematic review of emergency department crowding: causes, effects, and solutions. Ann Emerg Med. 2008;52(2):126-136.e1.

8 Clark EG, Watson J, Leemann A, Breaud AH, Feeley FG, Wolff $\mathrm{J}$, et al. Acute care needs in an Indian emergency department:A retrospective analysis. World J Emerg Med. 2016;7(3):191-5.
9 Lim KH, Yap KB. The presentation of elderly people at an emergency department in Singapore. Singapore Med J. 1999;40(12):742-4.

10 Singal BM, Hedges JR, Rousseau EW, Sanders AB, Berstein E, McNamara RM, et al. Geriatric patient emergency visits. Part I: Comparison of visits by geriatric and younger patients. Ann Emerg Med. 1992;21(7):802-7.

11 Rosenfeld T, Fahey P, Price M, Leeder S. The fate of elderly patients discharged from the accident and emergency department of a general teaching hospital. Community Health Stud. 1990;14(4):365-72.

12 Richardson DB. Elderly patients in the emergency department: a prospective study of characteristics and outcome. Med J Aust. 1992;157(4):234-9.

13 Shen Y, Teo EWK, Liu N, Lam SW, Ong MEH. Data-driven approach to defining the emergency department frequent attender using a cohort of 10 years - Paper presented at SGH 22nd Annual Scientific Meeting, 2017 April 7-8; Singapore.

14 Yip WL, Fan KL, Lui CT, Leung LP, Ng F, Tsui KL. Utilization of the Accident \& Emergency Departments by Chinese elderly in Hong Kong. World J Emerg Med. 2015;6(4):283-8.

15 McCusker J, Healey E, Bellavance F, Connolly B. Predictors of repeat emergency department visits by elders. Acad Emerg Med. 1997;4(6):581-8.

16 Lamantia MA, Platts-mills TF, Biese K, Khandelwal C, Forbach C, Cairns CB, et al. Predicting hospital admission and returns to the emergency department for elderly patients. Acad Emerg Med. 2010;17(3):252-9.

17 McCusker J, Cardin S, Bellavance F, Belzile E. Return to the emergency department among elders: patterns and predictors. Acad Emerg Med. 2000;7(3):249-59.

18 Philips GA, Brophy DS, Wieland TJ,Chenhall AJ, Dent AW. The effect of multidisciplinary case management on selected outcomes for frequent attenders at an emergency department. Med J Aust. 2006;184(12): 602-6.

Received April 22, 2017 Accepted after revision September 20, 2017 